\title{
Professor Kenji Mori, 21 March 1935-16 April 2019
}

\section{Wittko Francke ${ }^{1}$}

Published online: 3 September 2019

(C) Springer Science+Business Media, LLC, part of Springer Nature 2019

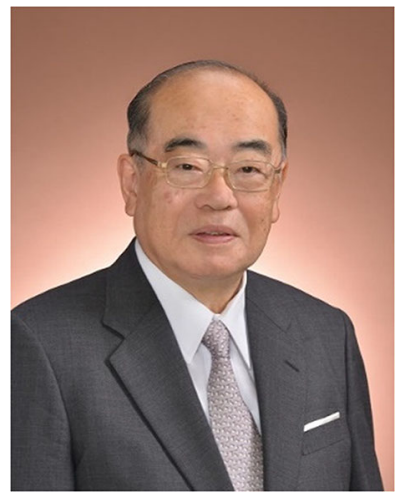

1981, Professor Kenji Mori receiving the Japan Academy Award in the presence of Emperor Hirohito.

Professor Kenji Mori was the son of a pastor and grew up in Okayama, Japan. His father introduced him to nature and agriculture, and throughout his life Kenji was guided by his Christian faith, kindness and compassion.

Kenji Mori studied chemistry at the University of Tokyo where he obtained a Bachelor degree in Agricultural Chemistry (1957). The subject of his $\mathrm{PhD}$ thesis, carried out with Professor M. Matsui, was the total synthesis of gibberellins (1962), a group of complex plant-produced diterpenes. He held the position of Associate Professor at the Department of Agricultural Chemistry of the University of Tokyo until 1978, when he became Full Professor at the Department of Agricultural Chemistry. After his retirement (1995) he continued at the Department of Chemistry of the Science University of Tokyo (until 2001) and worked with several Japanese companies and institutes as a consultant, especially at RIKEN (since 2003).

Wittko Francke

wittko.francke@chemie.uni-hamburg.de

1 Fachbereich Chemie, Institut für Organische Chemie, Martin -Luther-King-Platz 6, 20146 Hamburg, Germany
The concept of asymmetry in bioorganic chemistry was a driving force in Kenji Mori's scientific work. Approaching this area from the perspective of preparative organic chemistry, studies on the synthesis of bioactive natural products remained the focus of his research activities. He was a pioneer on the significance of stereochemistry in biologically active natural products, and for more than 45 years he was exceptionally productive in the field of asymmetric synthesis. His constant input and demand for nothing less than excellence was a decisive stimulus towards understanding the importance of stereochemistry in chemical signalling within and between organisms.

Large parts of Kenji Mori's work dealt with semiochemistry and chiral discrimination. He was the first one to show the importance of enantiomeric composition in chiral volatile signals by synthesizing the pheromones of Khapra beetles (Trogoderma spp. 1973) and Ips bark beetles (1974). His enantioselective syntheses of many insect pheromones are unparalleled contributions to our basic knowledge of insect pheromone chemistry. As an untiring, enthusiastic, and efficient mediator between chemistry and biology, Kenji generously supported legions of biologists and chemists with large amounts of extremely pure test materials and reference samples, providing indispensable tools for progress in many other labs all over the world. Determination of the absolute configuration of a multitude of chiral natural products is based on his synthetic compounds, and chiral synergism and chiral inhibition could be investigated and quantified through his work. His book on "Chemical Synthesis of Hormones, Pheromones and Other Bioregulators" (Wiley 2010) has a strong autobiographic touch.

In many of his more than 1200 frequently cited publications (research papers, monographs, and review articles) Kenji Mori was single author or the only chemist among biologists. With a proud smile Kenji used to say: "I did it with my own hands". Throughout his scientific life, his wife Keiko did most of the typing - thank you, Keiko. Making use of his experience, he was a highly esteemed board member of 15 international journals and a member of the Science Council of Japan (1988-1999). As an eminent scientist, Kenji was a sought 
after lecturer all over the world and received many prestigious awards, including: Agricultural Chemistry Award (1965, Agric. Chem. Soc. Japan), Japan Academy Award (1981, Japan Acad.), Agricultural Societies Prize (1992, Fed. Agric. Soc. Japan), ISCE Silver Medal (1996, Int. Soc. Chem. Ecol.), Fujiwara Prize (1997, Fujiwara Found. Sci.), Ernest Guenther Award (1999, Am. Chem. Soc.), František Šorm Memorial Medal (2003, Acad. Sci. Czech Rep.), Chirality Medal (2010, Soc. Chim. Italiana), Life Time Achievement Award (Asia-Pacific Ass. Chem. Ecologists). Since 2015 Kenji was a member of the Japan Academy, and at the ISCE meeting in Kyoto (2017), the Society named him Honorary Life Member.

Promoting "his" scientific communities, Kenji Mori was untiring in the use his industrial connections in many fundraising campaigns, which were highly impactful especially during the early years of the ISCE. And to underline his relations to the ISCE, he took the responsibility as the Society's President in 1992/1993. Since Kenji always sought to encourage young scientists from East Asia to get into contact with colleagues from the West, he was one of the founders of the Asia-Pacific Association of Chemical Ecologists (APACE) and the first President of the new Society (1997-
1999) - and he was happy to see APACE quickly achieve remarkable success.

Professor Kenji Mori was an exemplary ambassador for interdisciplinary research through dedication, inspiration, disciplinary rigor, and human understanding. He was Japanese at heart and soul, who travelled extensively, but never left Japan for a post doc or sabbatical. He was most pleased when he proclaimed, "from my flat I can see Mount Fuji and my lab". Until his last hours, he was working on a manuscript.

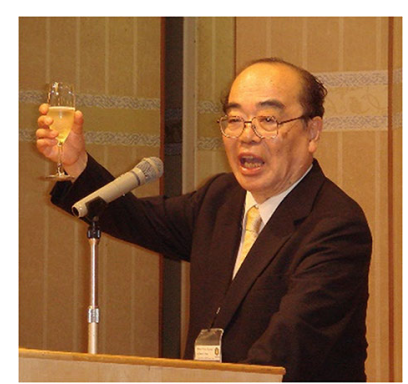

2007, Kenji Mori toasting the success of ISCE and APACE at the APACE meeting in Tsukuba, Japan. 